\title{
Risk management in wine industry: A review of the literature
}

\author{
Antonio Seccia, Fabio Gaetano Santeramo, and Gianluca Nardone \\ Department of Agricultural, Food and Environmental Sciences, University of Foggia, Foggia, Italy
}

\begin{abstract}
Wine industry is characterized by high added value, particularly for some segments. The quality of the final product is the result of the right combination of many variables which involve the choice of the suitable wine grape varieties to particular conditions of site location, soil, climate, landscape together with entrepreneurial right decisions in management. The globalization of the market with the increasing of competition among producers and the evidences of climate change, that has different effects on the vitivinicultural areas in the world, have led to the growth of frequency and intensity of risks that winegrowers have to cope with. Their behaviour and reactions in managing risky situations of different nature, often adopting instruments they are not familiar with, as insurance or derivatives, could result in relevant consequences on prices, costs of production, revenues and profits, in other words, on the value chain of the wine production. This paper aims to provide a general overview of the economic literature on risk management in the wine industry.
\end{abstract}

\section{Introduction}

Management of risks in wine production is reaching growing interest since there is widespread evidence that they have grown rapidly over the recent past in all categories of food production [1]. Like all the agricultural sectors, wine market is subjected to many risks originated by several factors: human behavior, climate, production processes, price fluctuations, institutional and policy framework, economic and financial risks [2,3]. Wine industry is characterized by added value which is higher compared to other sectors, with the production of diversified products, in some cases with very high unit value so, facing risks, producers can lose a part or the complete production in very short time, finding themselves in a serious financial situation. There is an increasing evidence that such risks affect several actors in the wine industry besides producers: insurers, consumers, traders, retailers, investors, government institutions and policy makers.

Scientific literature classifies risks in agricultural production on the basis of the origin of uncertainty (price, yield), the scale of the event (idiosyncratic and systemic risks), the frequency of it (rare or more frequent events) and the intensity of its consequences. Producers can cope with risks undertaking various risk management instruments, in some cases to prevent the negative effects of risky activities (ex ante) and in others to reduce their consequences (ex post). Such instruments imply either direct or opportunity costs and their application is limited by the presence and accessibility of their markets that can be missing or incomplete [4].

Empirical evidence shows that farmers are characterized by risk aversion when they deal with economic or production decisions [5]. However, despite such apparent need for risk management, it is evident a very weak use of financial coverage instruments (insurance, weather derivatives, forward contracts, etc.) because producers are reluctant in purchasing a financial solution, considered too expensive and complicated [6,7]. The modest development of financial tools is usually considered as a justification for the intervention of the government which takes on most agricultural risks, but opinions about the efficiency of policy interventions and government subsidies are divergent.

The purpose of this paper is to provide an overview of the economic literature on risk management in wine production paying attention to the broad range of typologies and severity of risks. In particular, the review will identify and discuss how scholars have analyzed these subjects covering different topics: the main sources and characteristics of risks, strategies (prevention, mitigation, adaptation), dispositions (informal, market based, public) and instruments. The review will provide useful insights for both practitioners and policy makers and indications for possible trajectories for future researches.

\section{An overview of the economic literature on risk management in wine industry}

\subsection{Climatic risks}

Grapevines are a geographically expressive crop, being grown in distinct climate regimes worldwide that provide the ideal conditions to produce high-quality grapes but, on the other hand, such very close association with the climate makes the crop very sensitive to the fluctuations in weather conditions. So, impacts of climate changes are reflected on yield and on the quality of grapes and wine, resulting in consequences on prices, costs of production, revenues and profits of growers and winemakers [8]. With rising interest in climate change and its consequences on wine production, a growing body of literature has been studying 
the different risks that grapes growers and winemakers are already facing or will face in the future.

With regards to responses of mitigation and adaptation to climate change in the wine industry, Galbreath [9] has introduced a model which considers risks in the two processes of grape producing and winemaking. The framework is built on the basis of the literature and the experts' opinions. Mitigative and adaptive responses have been shaped covering the technology and process concerns which wine producers can adopt to address risks sustainability. Actions are referred to three fields: market, regulatory/standards and operational. The framework has been applied to a big Australian wine producer, Treasury Wine Estates (TWE), showing that mitigative and adaptive reactions rely on the various technologies and processes at the different levels.

In most contexts, an effective tool to face risks is insurance but in the agriculture sector a specific instrument as weather insurance has had limited diffusion because of the complexity in defining the proper weather event and in determining the price of the product. Turvey et al. [10] have developed an innovative method to determine the price for weather insurance in circumstances where returns are influenced not only by the occurrence of the weather event but also by its timing. The authors developed a Monte Carlo method to estimate the insurance premium, considering the case of ice wine in the Niagara Peninsula of southern Ontario.

Besides traditional financial instruments as insurance, the use of innovative financial solutions must also be sought in order to deal with many of the financial risks arising from climate change. Among them, the market of weather derivatives is generally increasing even though in the case of the agricultural sector they have had a low diffusion, according some authors because of a lack of familiarity and a clear understanding of the benefits [11]. Studies about their use are very few and only recently scholars have devoted attention to them [12]. Among them, Cyr and coauthors have examined the adoption of weather contracts in different situations specific to the province of Ontario, Canada. The risk of hotter temperatures during the harvest of icewine grapes has been examined by Cyr and Kusy [13] while the risk of low temperatures in wintertime has been analyzed by Cyr et al. [14]. Considering the increasing variability of rainfall in the Northern Hemisphere consequently to climate change, Cyr et al. [15] have explored the adoption of weather contracts to hedge the financial risk consequential to the excess of rainfall during the grapes harvest period. Taking into account different contract hypothesis, they aimed to evaluate a range of benchmark call option value using rainfall data to develop a stochastic method for cumulative harvest rainfall with reference to the Niagara region. A case study regarding California has been considered by Cyr et al. [16] who used a stochastic method of a cumulative weather variable over a time period, and adopted a copula function technology to process a model for the pricing of a weather contract. The usefulness of weather derivatives in the wine industry, for covering climate risk considering bioclimatic indices to mitigate the risk of growing season temperatures, has been analyzed by $\mathrm{Cyr}$ et al. in the Niagara region of Canada [17] and by Zara in the Oltrepo Pavese area of Italy [18]. Zara [19] has also considered the potential design of weather contracts developing an appropriate temperature risk hedging strategy to reduce the unpredictability that affects grapes economic results. The strategy is based on the development of a risk definition process which includes the identification of a representative heat summation index ratio between temperature and yield. He applied the strategy to a case study referred to the Bourgogne Côte de Nuits Pinot Noir red grape. Simulations carried out demonstrate that the strangle strategy covers the climate risk in a better way reducing crop volatility. Results from the study prove that it is possible to hedge the winemaker's crop with weather derivatives which are more flexible and transparent compared to insurance policies.

\subsection{Producers' perception of risks}

A relevant concern related to climate change is the consequence on farmers' welfare which is affected by the perception they have of the agricultural risks. How they perceive impacts plays a fundamental role in responding to them engaging in mitigation or adaptation strategies. The research realized by Menapace et al. [20] considers risk perceptions for Italian producers related to risk of damages on production caused by climate events. To such purpose, they perform an elicitation of the median of the subjective beliefs cumulative distribution of crop losses risk, using the exchangeability method. Results show that growers' perceptions for the long-run are considerably higher than for short-run and the reason of such difference can be found in climate change individual convictions and personal experience with past production damages. Given the crucial role of past experiences, it would be useful to consider segments of growers with different climate change beliefs and to improve growers' awareness of potential risks proposing them a better assistance to adapt to climate fluctuations.

The conduct of wine producers under general risky circumstances has also been the subject of a field research conducted by Salk et al. [21] who have interviewed wine producers in the Maine-et-Loire department using a questionnaire about their perception of climate risks and their strategies to address them. Given the increase of costs as a consequence of climate change, the aim of the study was to understand the reasons of the very low diffusion of tools as insurance or weather derivatives. Results show that the behavior of the producers is paradoxical because, although they need to face risks, financial instruments are deemed costly and too difficult to understand and to manage.

The motivations behind grape growers purchase intentions regarding risk management insurance have been analyzed by Lobos et al. [22] who have realized an empirical study with the aim to find the determinants that affect the probability of subscribing insurance contracts in the Chilean wine industry. The authors have considered two discrete selection models (logit and probit) to detect the producer's individual characteristics and they can infer about the impact that a set of socioeconomic variables and the producers' own opinion have on the willingness to buy insurances. Results of the analysis show that the significant explanatory variables are associated mostly to the producers' perceptions in terms of getting access to prices and wine markets, awareness of sanitary risk and the opinion of an adequate management of risk. Among the 
socioeconomic variables, only the area planted with wine grapes resulted to be significant.

\subsection{Markets and prices risks}

Wine grape producers are aware that they have to face both production and market risks. An economic analysis realized by Folwell et al. [23] considered both kinds of risks with reference to three varieties grown in Washington State: Cabernet Sauvignon, Chenin Blanc and White Riesling. The production risk has been considered with reference to unexpected lower yields caused by less fruit buds flowering as a consequence of low temperatures in wintertime. The market risk has been considered in terms of prices fluctuations as result of changes in the market supply and demand. The authors realized a simulation model which includes both kinds of risk at the same time taking into account the costs of production and prices by the combination of weather effects on bud kills and yields; moreover, as a basic assumption, the producer did not take any risk management strategies.

Climate events and market unpredictability affect considerable revenue variability for winegrowers as a consequence of volatile prices and yields. Since the EU is going to reduce wine market subsidies, it could be helpful to explore more market-oriented risk management instruments. To such purpose, Ramirez et al. [24] have simulated actuarially fair premiums for revenue insurance contracts in the Spanish wine industry. These kind of contracts are a market-based risk management innovation that can support farmers to cover revenue losses that arise from adverse yields, prices or both. The authors have applied a contingent claims analysis valuation framework and Monte Carlo simulation. The model shows that revenue insurance premiums could have a lower cost than similar multi-peril insurance products and price supports programs; moreover, revenue insurance can provide Spanish wine grape producers with income stabilization that does not alter trade like current subsidy programs.

The rapid international expansion of the wine industry has increased the need to comprehend wine price risk and the strategies to reduce it. Prices are sensitive to climate variations and cannot be determined correctly prior to production since inelastic demand translates into high price uncertainty leading to widespread economic and financial implications. Kourtis et al. [31] have analyzed the risk arising from the fluctuations in fine wine prices evaluating the possibility for firms to diversify the production across countries and wine varieties. They focus on financial instruments that can be adopted to address the risk management and improve market completeness as derivatives, futures and options contracts.

\subsection{Relevance of data and information availability in managing risk}

In risk management a crucial role is played by information and availability of data. Agronomic data from observed crop yields have been used by a big insurance group, Groupama, to develop a simulation process to estimate the insurance premium. As reported by Phélippé-Guinvarc'h [25], data provided by a French wine cooperative were used to apply a general model of agronomic crop yield density function, already tested for other products. In the case of wine, the application of the model is disturbed by public regulations which limit yields (in the case of denominations of origin) and quality regulations applied by some cooperatives.

The management of disease and pests by growers has improved in consequence of the better accuracy of weather, pest and disease forecast information that are available for them as a useful tool for preventing risks and shaping their behavior. Given that the strategies adopted by farmers to prevent risks have implications at both local and social level, it should be necessary to know more how the availability of information influences producers' strategies. To such purpose Lybbert et al. [26] have conducted an empirical analysis concerning the effect of improved disease forecast information on grape growers' behavior and on the environment. Temporal and spatial data concerning treatments for powdery mildew in California were used to estimate models of producers' disease management procedure. Results show that responses differ according to location and product value.

\subsection{Relevance of investments in knowledge and technology}

Knowledge has relevant importance to address the different types of risks for an enterprise. In an empirical study Dutz et al. [27] have analyzed the links between Knowledge-Based Capital (KBC) investments and export for the wine industry in Chile. Such investments play a critical role in supplying enterprises with necessary competences to predict, take in and modify behavior to risks. The authors highlighted that for the Chilean wine industry $\mathrm{KBC}$ investments can be considered important assets for firms' risk management. The research gives a particular focus on the importance of KBC investments for addressing risks related to innovation and on the crucial linkages between investments in knowledge, protection/enabling and insurance and coping/leveraging assets.

The value of the wine is greatly influenced by quality and particularly by the preservation of it during storage when wine is highly sensitive to variables as temperature and humidity that could alter the quality. This is a critical concern for wineries and distributors which have to manage risk under storage facilities for maintaining wine quality and preventing the depreciation in value. So, it is crucial to control and monitor risk during wine storage to preserve wine quality. For monitoring real-time storage conditions of wine and for planning an immediate strategy for handling unpredicted events, Lam et al. [28] proposed a risk control and monitoring system (RCMS) which combines the technology of radio frequency identification (RFID) and case-based reasoning (CBR). The RFID tag has sensors for temperature and humidity which measure the actual storage condition of each stock keeping unit (SKU) of wine and all information about the wine and its location are available in order to find easily the product with anomalous measurements. The case-based reasoning (CBR) can generate, taking into account past similar event cases, a shortlist of critical control actions, on the basis of possible causes of incidents and subsequent activities. The adoption of the RCMS allows the development of effective operative plans and to reach the reduction in the 
wine damage of quality with the improvement in customer satisfaction.

\subsection{Risks and transaction costs}

A peculiar kind of risk concerns the market relationships between different enterprises and transaction costs. This issue has been considered by Franken and Bacon [29] who have analyzed the role of vertical coordination strategy in decreasing the risks concerned to the procurement of required quality grapes. They report a study realized in California highlighting that formal written contracts stipulated for grapes procurement are more reliable than informal agreements because of the risk associated to the purchase of the required quality grapes. Perishability of grapes, both physiological and unpredicted because of climatic events, could make difficult or uncertain, or sometimes costly, the procurement of desired quality grapes, so strategies of vertical integration are necessary using detailed written contracts. In some cases, when quality is very difficult to evaluate and the winemaker needs to check also production practices, could be necessary a complete vertical integration which leads to the ownership of consecutive stages in the supply chain. The issue of contracts as a strategy to face marketing and provision risks in the wine industry has also been studied by Steiner [30] who has considered that a relationship between a producer and a winery is characterized by a condition of moral hazard which involves both sides. He has developed a comparative static outcomes for optimal sharing rule in a principal-agent model where both principal (winery) and agent (grape producer) are considered to carry out multiple tasks. As basic assumption, the role of a grape grower to the final wine quality consists in production while the contribution of the winery is realized in processing and marketing stages. Both parties could act as opportunists since efforts of both sides are mutually imperfectly detected and their impact on final quality of the product can only be inaccurately evaluated. The model allows for asymmetric quality contributions of the contracting parties, and shows that, in case of risk-aversion for both parties, strict sharing can also be supported in bilateral moral hazard settings.

\section{Conclusions}

The present paper has provided a general overview of the economic literature on risk management in the wine industry. The interest of researchers on this field is recent so the scientific production is quite limited but growing. Most papers consider the risks arising from climate change and the strategies that winegrowers could adopt to address such risks, particularly financial instruments as insurances and weather contracts. Many of them are referred to specific areas so it should be useful to study the same issues and to apply the same methodologies considering more vitivinicultural areas in the world. Moreover, additional issues, not still covered for the wine industry, need to be considered. At farming level, it would be very interesting to study producers' decisions under risk and their choices to address different types of risks, taking in consideration costs and revenues, including costbenefit analysis. According to the specificity of the region, growers should adopt measures to address risks that vary in their economic feasibility and barriers to implementation.

Future studies could analyze the experience in the formation of opinions about kinds of risks among winegrowers and the gap between their need to cope with risk and the adoption of proper instruments. A related issue is to understand the role of factors that might drive the implementation of such instruments in firms and its impacts on business outcomes.

A new field of study concerns social consequences of the management of different risks and their impact on the regional cultural identity considering that highquality wine regions create unique physical and cultural landscapes that, through growing, processing, trade, and tourism, are crucial components of local economies.

At an international level, further studies should consider the management of risk in the conglomerate beverage companies with multinational landholding portfolios which have worldwide strategic investments.

The role of institutions and policy interventions should be analyzed in consideration of subsidies which, in some contexts, are given to farmers to address the risk of negative climatic events. The arising of risks of different typology, due to climate change, globalization of the market, fluctuation of prices, moral hazard of agents, underscore the need for flexible agricultural policies and requirements for grape growers and wine producers to adopt proper risk management schemes.

\section{References}

[1] OECD "Risk management in agriculture" - A holistic framework. Paris (2009)

[2] S. Kimura, J. Antón, C. LeThi, "Farm level analysis of risk and risk management strategies and policies (2010)

[3] A. Kourtis, R. N. Markellos, D. Psychoyios, "Wine price risk management: International diversification and derivative instruments", International Review of Financial Analysis, 22, 30-37 (2012)

[4] F. G. Santeramo, J. Di Pasquale, F. Sgroi, "Analyzing risk management in Mediterranean Countries: the Syrian perspective", New Medit, 11(3), 35-40 (2012)

[5] P. Sulewski, A. Kłoczko-Gajewska, "Farmers' risk perception, risk aversion and strategies to cope with production risk: an empirical study from Poland" Studies in Agricultural Economics, 116(3), 140-14 (2014)

[6] EU Commission "Risk management tools for EU agriculture with a special focus on insurance", Working Document, Agriculture Directorate-General (2001)

[7] J. Viviani, "Protection against wine price risks: A real option approach", Journal of Wine Economics, 2, 168-186 (2007)

[8] G.V. Jones, L.B. Webb, "Climate change, viticulture, and wine: challenges and opportunities", Journal of Wine Research, 21(2-3), 103-106 (2010)

[9] J. Galbreath, "Response to the risk of climate change: A case study of the wine industry" (No. 231251), AAWE Working Paper No. 181 (2015)

[10] C. G. Turvey, A. Weersink, S. H. C. Chiang, "Pricing weather insurance with a random strike price: The Ontario ice-wine harvest", American Journal of Agricultural Economics, 88(3), 696-709 (2006) 
[11] J. Gedeon, "Wine industry is slow to warm up to weather derivatives: experts say various factors account for hesitation", Wine Business Monthly, 15 June (2008)

[12] D. Cyr, M. Kusy, A. B. Shaw, "The potential use of weather derivatives in the viticulture industry", Economia e Diritto Agroalimentare, 13(3), 67-81 (2008)

[13] D. Cyr, M. Kusy, "Canadian icewine production: a case for the use of weather derivatives", Journal of Wine Economics, 2, 1-23 (2007)

[14] D. Cyr, M. Kusy, A. Shaw, "Hedging the risks of vineyard winter injury with an OTC collar contract", Working paper, Brock University (2009)

[15] D. Cyr, M. Kusy, A. B. Shaw, "Climate change and the potential use of weather derivatives to hedge vineyard harvest rainfall risk in the Niagara region", Journal of Wine Research, 21(2-3), 207-227 (2010)

[16] D. Cyr, R. Eyler, M. Visser, "The Use of Copula Functions in Pricing Weather Contracts for the California Wine Industry" (2013)

[17] D. Cyr, M. Kusy, A. B. Shaw, "Hedging adverse bioclimatic conditions employing a short condor contract", Journal of Wine Economics, 3, 149-171 (2008)

[18] C. Zara, "La gestione dei rischi climatici nel settore vitivinicolo", Economia and Management, Vol. 5, pp. 13-29 (2008)

[19] C. Zara, "Weather derivatives in the wine industry", International Journal of Wine Business Research, Vol. 22 Iss 3 pp. 222-237 (2010)

[20] L. Menapace, G. Colson, R. Raffaeli, "Farmers' Climate Change Risk Perceptions: An Application of the Exchangeability Method", EAAE 2014 Congress 'Agri-Food and Rural Innovations for Healthier Societies' August (Vol. 26) (2014)

[21] S. B. Salk, S. Blondel, C. Daniel, C. DeffainsCrapsky, C. Jutard, B. Sejourne "Management of Climate Risks in the wine sector", 101st EAAE Seminar 'Management of Climate Risks in Agriculture', Berlin, Germany, July 5-6, 2007 (2007)

[22] G. Lobos, J. L. Viviani, B. Schnettler, N. Muñoz, A. Reyes, "Predicting probability to purchase insurance contracts in the Chilean wine industry: a logit and probit comparative analysis", Ciência Téc. Vitiv, 25(2), 41-51 (2010)

[23] R. J. Folwell, B. Gebers, R. Wample, A. Aegerter, T. Bales, "Production and marketing risks associated with wine grapes in Washington", Washington State Univ., College of Agriculture and Home Economics Research Center (1997)

[24] A. Ramirez, M. Manfredo, D. R. Sanders, "Revenue Insurance for Spanish Wine Grapes", Journal of International agricultural Trade and Development, Vol.1 N. 2 pp.149-168-167 (2005)

[25] M. Phelippe-Guinvarc'h, "Weather Insurance of Wine-How Quantity and Quality Regulations Affect Risks", In 101st Seminar, July 5-6, 2007, Berlin Germany (No. 9258). European Association of Agricultural Economists (2007)

[26] T. J. Lybbert, N. Magnan, W. D. Gubler, "Powdery Mildew Risk And Forecasting In Wine Grapes: Do Growers Change Risk Management Strategies" In Response To Disease Forecasts?. In 2010 Annual Meeting, July 25-27, 2010, Denver, Colorado (No. 61745). Agricultural and Applied Economics Association (2010)

[27] M. A. Dutz, S. D. O’Connell, J. L. Troncoso, "Public and private investments in innovation capabilities: structural transformation in the Chilean wine industry", World Bank Policy Research Working Paper, (6983) (2014)

[28] H. Y. Lam, K. L. Choy, G. T. Ho, C. K. Kwong, C. K. M. A. Lee, "A real-time risk control and monitoring system for incident handling in wine storage", Expert Systems with Applications, 40(9), 3665-3678 (2013)

[29] J. R. Franken, K. J. Bacon, "Organizational structure and operation of the Illinois wine industry", Agricultural and Resource Economics Review, 43(1), 104-124 (2014)

[30] B. Steiner, "The Extent and Nature of Contracting in the Wine Supply-Chain When Moral Hazard is Present", Department of Rural Economy, Faculty of Agricaltural, Life and Environmental Sciences, University of Alberta (2009) 